\title{
Effect of Heat Treatment on the Optical Properties of Cobalt Doped Stannic Oxide
}

\author{
Saba Jameel Hasan \\ Physics Department, Education College, Al-Mustansiriyah University, Baghdad, Iraq \\ E-mail address: Jameel.saba@yahoo.com
}

\begin{abstract}
This study investigates The effect of annealing on The optical properties of $\left(\mathrm{SnO}_{2}: \mathrm{Co}\right)$ films prepared by spray pyrolysis (SP) technique at a glass substrate temperature (Ts $=773 \mathrm{~K})$. The absorbance and transmittance spectra have been recorded in order to calculate the optical constant and the optical band gap energy of the films. It was found that the annealing affects all the parameters under investigations.
\end{abstract}

Keywords: thin films; chemical spray pyrolysis; dilute magnetic semiconductor; stannic oxide; doping

\section{INTRODUCTION}

The (TCOs) films are the most appropriate material for many applications. Tin oxide seems to be the one of the most interesting material which are chemically inert, mechanical hard and heat-resistant. They exhibit low electrical resistivity and high optical transmittance $[1,2]$, tin oxide films are stable at high temperatures, have excellent resistant to mechanical wear, and have very good adhesion to many substrates $[3,4]$. $\left(\mathrm{SnO}_{2}\right)$ is a crystalline solid with tetragonal crystal lattice. It is a wide band gap, non-stoichiometric semiconductor , and also can be exist into two transitions, having direct and indirect optical transition, a direct band gap that ranges from $3.6 \mathrm{eV}$ to $4.6 \mathrm{eV}$ at room temperature and indirect band gap of about $2.6 \mathrm{eV}$. The electric conductivity of these films can be enhanced by appropriate doping [5].

Tin oxide films are attractive for many optoelectronic devices such as solar cells [6], display and electrochromic device, electroluminescent display, imaging devices, protective coating, anti-reflection coating, gas sensors [7-9], due to the sensitivity of it is surface conductance to gas adsorption, light emitting diodes. Currently, a large number of techniques exist for the preparation of $\mathrm{SnO}_{2}$ films. These include if sputtering, magnetron sputtering, vacuum evaporation, atmospheric pressure chemical vapor deposition, thermal evaporation, sol-gel dip coating and spray pyrolysis [10-13]. The spray pyrolysis method is most commonly used due to the simple process and economic advantages. In addition, tin oxide prepared by spray technique is also physically and chemically resistant against environmental 
effects and adheres strongly to different substrate. The aim of this work was subjected to the effect of annealing at $823 \mathrm{~K}$ on the optical constants of the deposited thin films [16-22].

\section{EXPERIMENTAL DETAILS}

For the deposition of $\left(\mathrm{SnO}_{2}\right)$ thin film the following metallic salt solution including $(3.50 \mathrm{~g})$ from of $\left(\mathrm{SnCl}_{4} \cdot 5 \mathrm{H}_{2} \mathrm{O}\right)$ and $(100 \mathrm{ml})$ redistilled water was used to get an aqueous solution with concentration $(0.1 \mathrm{M})$, for deposition $\left(\mathrm{SnO}_{2}: \mathrm{Co}\right)$ Thin films, certain amounts of $\mathrm{CoCl}_{2} \cdot 2 \mathrm{H}_{2} \mathrm{O}$ are added to the initial solution as (3-5\%) without any changes in the clarity of the solution.

Table 1. The volumetric percentage of the prepared thin films.

\begin{tabular}{|c|c|c|}
\hline Percent & $\mathrm{SnCl}_{2} \cdot 5 \mathrm{H}_{2} \mathrm{O}$ & $\mathrm{CoCl}_{2} \cdot 2 \mathrm{H}_{2} \mathrm{O}$ \\
\hline 0 & 100 & 0 \\
\hline $3 \%$ & 97 & 3 \\
\hline $5 \%$ & 95 & 5 \\
\hline
\end{tabular}

Table 1 represents the volumetric percentage of the prepared solution The $\left(\mathrm{SnO}_{2}\right)$ and $\left(\mathrm{SnO}_{2}: \mathrm{Co}\right)$ thin films which were deposited on a glass substrate with size $\left(2.5 * 2.5^{*} 0.1\right) \mathrm{cm}^{3}$ using spray pyrolysis technique. The deposition apparatus consisted of as pray chamber, hot plate and air as a carrier gas. The optimum condition, arrived at the followings: substrate temperature was $(725 \mathrm{~K})$, flow rate $5 \mathrm{ml} / \mathrm{min}$, distance between sprayer nozzle and substrate $29 \pm 1 \mathrm{~cm}$. The spraying time was $10 \mathrm{Sec}$ lasted by $2 \mathrm{~min}$ wait to avoid excessive cooling.

The optical absorption and transmission spectra of films, were recorded using (UVvisible-spectrophotometer (Schimadzu 1650 U-probe Japan) in the wavelength range (300900) $\mathrm{nm}$. In order to compare the absorbance of $\left(\mathrm{SnO}_{2}: \mathrm{Co}\right)$ thin films before and after annealing at $\left(350{ }^{\circ} \mathrm{C}\right)$ for 2 hours, three samples $(0 \%, 3 \%, 5 \%)$ Co concentration were selected and then their optical spectra in UV-Visible region were measured.

\section{RESULTS AND DISCUSSION}

Fig. 1 shows the absorbance before and after annealing, all the samples exhibit the same behavior. It was seen that the absorption edge shifts to longer wavelength with the increasing Co content (red shift). Which can be attributed to an increase in carrier density resulting in the occupation of the lower states of conduction band.

Fig. 2 shows the transmission before and after annealing for the all samples, it is clearly seen that the transmittance. The decrease in the transmission of the films with the increase of Co dopant for both before and after annealing and this might due to an increase in light scattering by the defect at $\mathrm{SnO}_{2}$ surface. We can see also that the value of transmittance after annealingis heigher than its value before annealing. The increase in transmittance might be attributed to the well crystallites after annealing.

The optical energy band gap was calculated using relation [14] 


$$
\alpha h v=A^{*}(h v-E g)^{r}
$$

(a) -Before

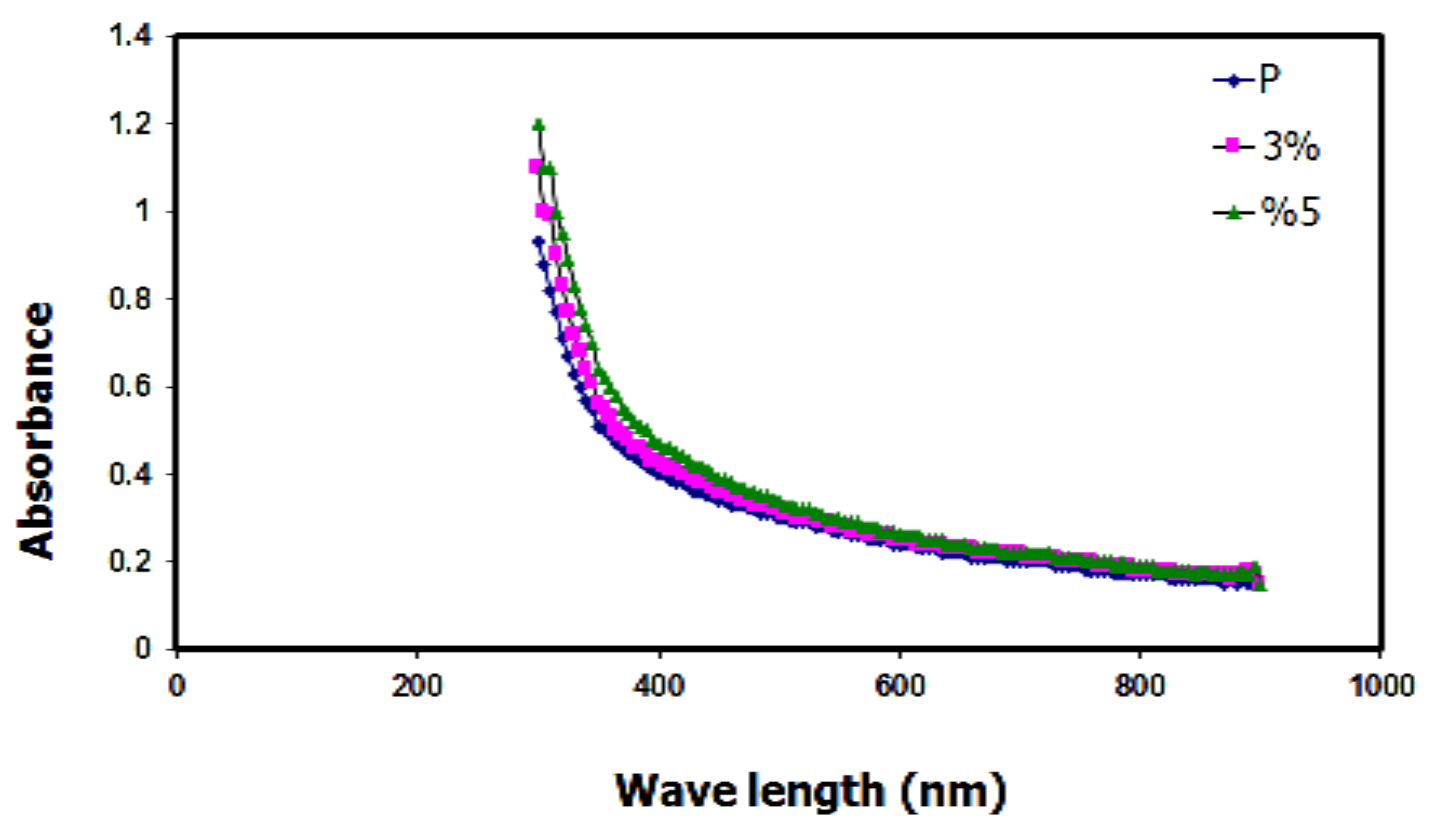

(b) - After

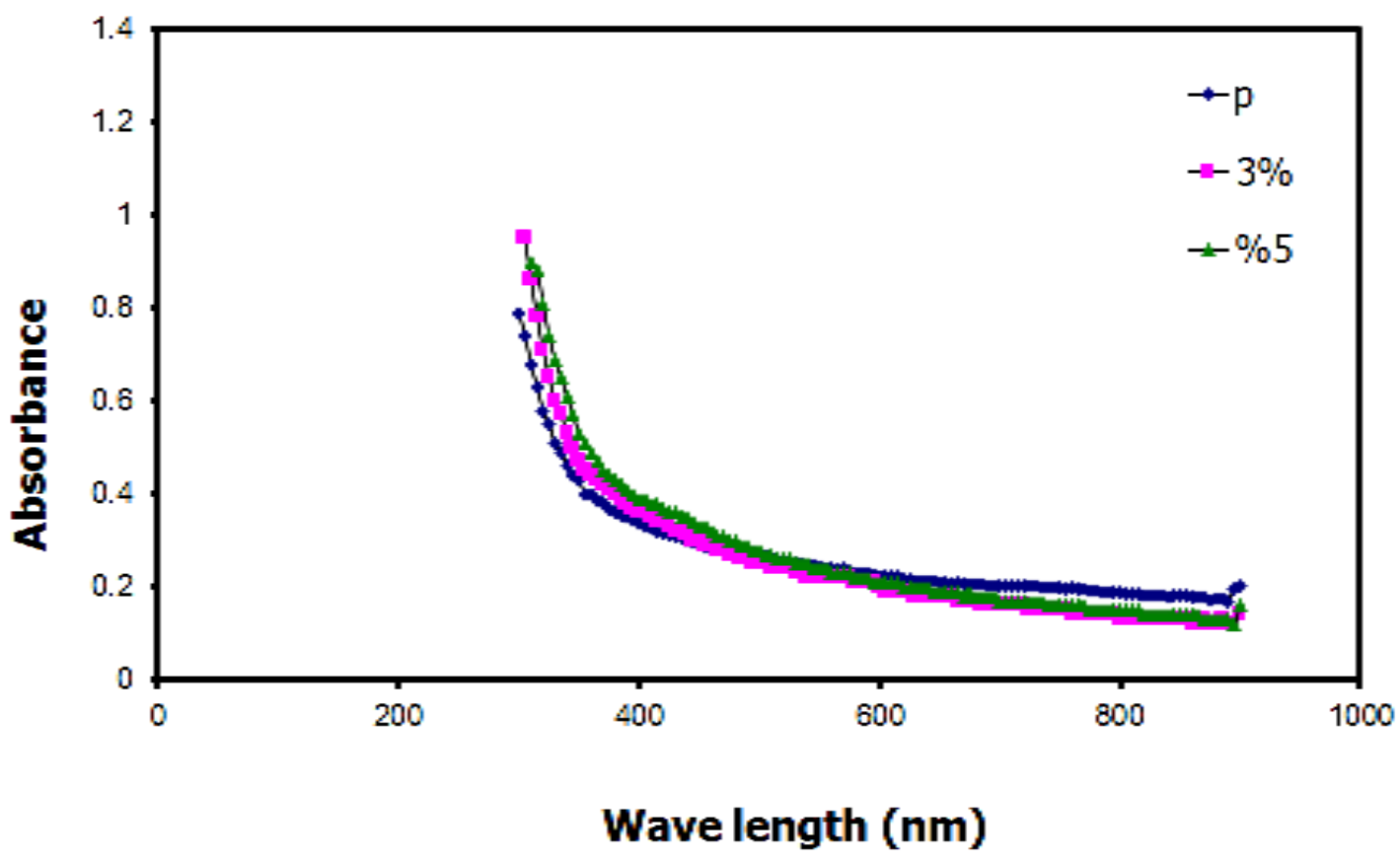

Fig. 1(a,b). Absorbance versus wavelength before and after annealing. 

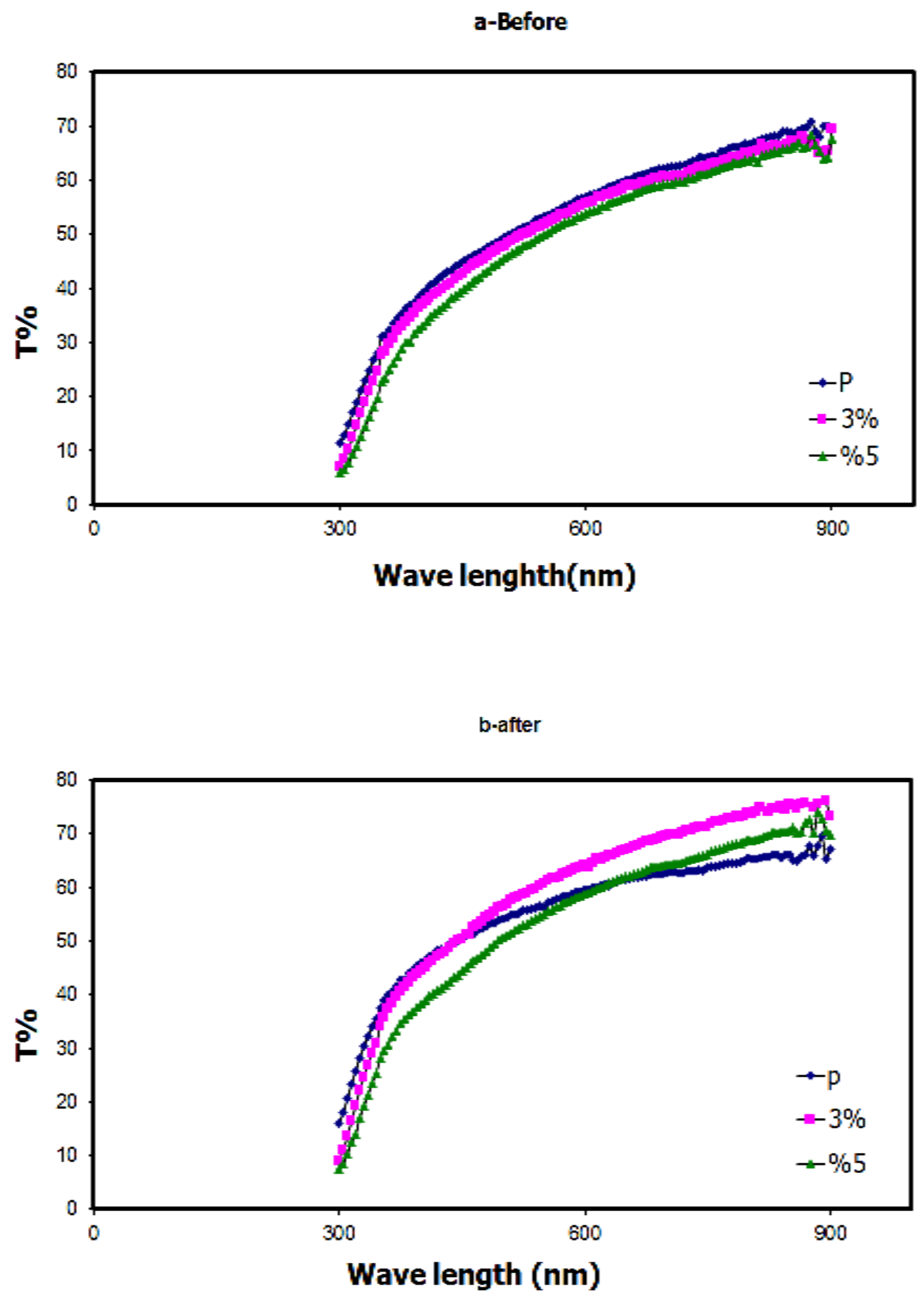

Fig. 2(a,b). Transmittance as a function of wavelength before and after annealing. 
where the exponent $\mathrm{r}$ could have the values $(1 / 2,3 / 2,2,3)$, depending on the type of electronic transition in K-space. The best fit for $(\alpha h v)$ as function of hv is obtained with $(r=$ $1 / 2$ ). As can be seen from Fig. $3(\alpha h v)^{2}$ as a function of photon energy, the optical energy gap decrease with the increasing of Co concentration before and after annealing for. The band gap energy is determined from the extrapolated straight line portion of the plot to the $\mathrm{x}$ axis, $(\mathrm{ahv})^{2}=0$. Table 2 represents the value of the optical energy gap for the as deposited and for annealed. It was seen that the value of optical energy gap increased after annealing in comparison with its value before annealing, this might be due to the increase in the concentration of free charge carriers and also the increase of grain size after annealing results in smaller effect of grain boundary.

Table 2. Direct forbidden transition for samples.

\begin{tabular}{|c|c|c|}
\hline sample & $\begin{array}{c}(\alpha \mathrm{hv})^{2} \text { before } \\
\text { annealing }\end{array}$ & $\begin{array}{c}(\alpha \mathrm{hv})^{2} \text { after } \\
\text { annealing }\end{array}$ \\
\hline Pure & 3.4 & 3.7 \\
\hline $3 \%$ & 3.3 & 3.6 \\
\hline $5 \%$ & 3.2 & 3.5 \\
\hline
\end{tabular}

The extinction coefficient, which calculated from the relation [15]

$$
\mathrm{K}_{\mathrm{o}}=\alpha \lambda / 4 \pi
$$

It can be seen from Fig. 4, that the extinction coefficient increases when the increasing in cobalt content in the ultraviolet region while their values are nearly constant in the visible region, this behavior was seen before and after annealing.

As shown in Fig. 5. The variation of refractive index with photon energy as deposited and annealed films have been determined by using the equation [15]:

$$
\mathrm{n}_{\mathrm{o}}=\left\{(1+\mathrm{R})^{2} /(1-\mathrm{R})^{2}-\left(\mathrm{K}_{\mathrm{o}}{ }^{2}+1\right)\right\}^{1 / 2}+(1+\mathrm{R}) /(1-\mathrm{R})
$$

where $\mathrm{R}$ is the reflectance, $\mathrm{K}$ is the extinction coefficient. It was found from this figure that the refractive index present a minimum value at a concentration of 3 at $\%$. This minimum could be explained by a certain level of porosity in the films together with the tendency for $\mathrm{Co}$ nanoparticles to fully oxidize leading to a sort of $\mathrm{SnO}_{2}-\mathrm{Co}$ mixed phase. For higher Co contents.

The higher value of refractive for the 5 at. \% Co-doped- $\mathrm{SnO}_{2}$ films could be explained by enlargement of Co particle size and an increase of their metallic character contribution. These results open up the possibility of tuning the optical characteristics of metal-doped$\mathrm{SnO}_{2}$ films. The refractive index increases after the heat treatment probably due to the increase of the compactness of the films after the heat treatment simultaneously to increase of the crystallite size. 

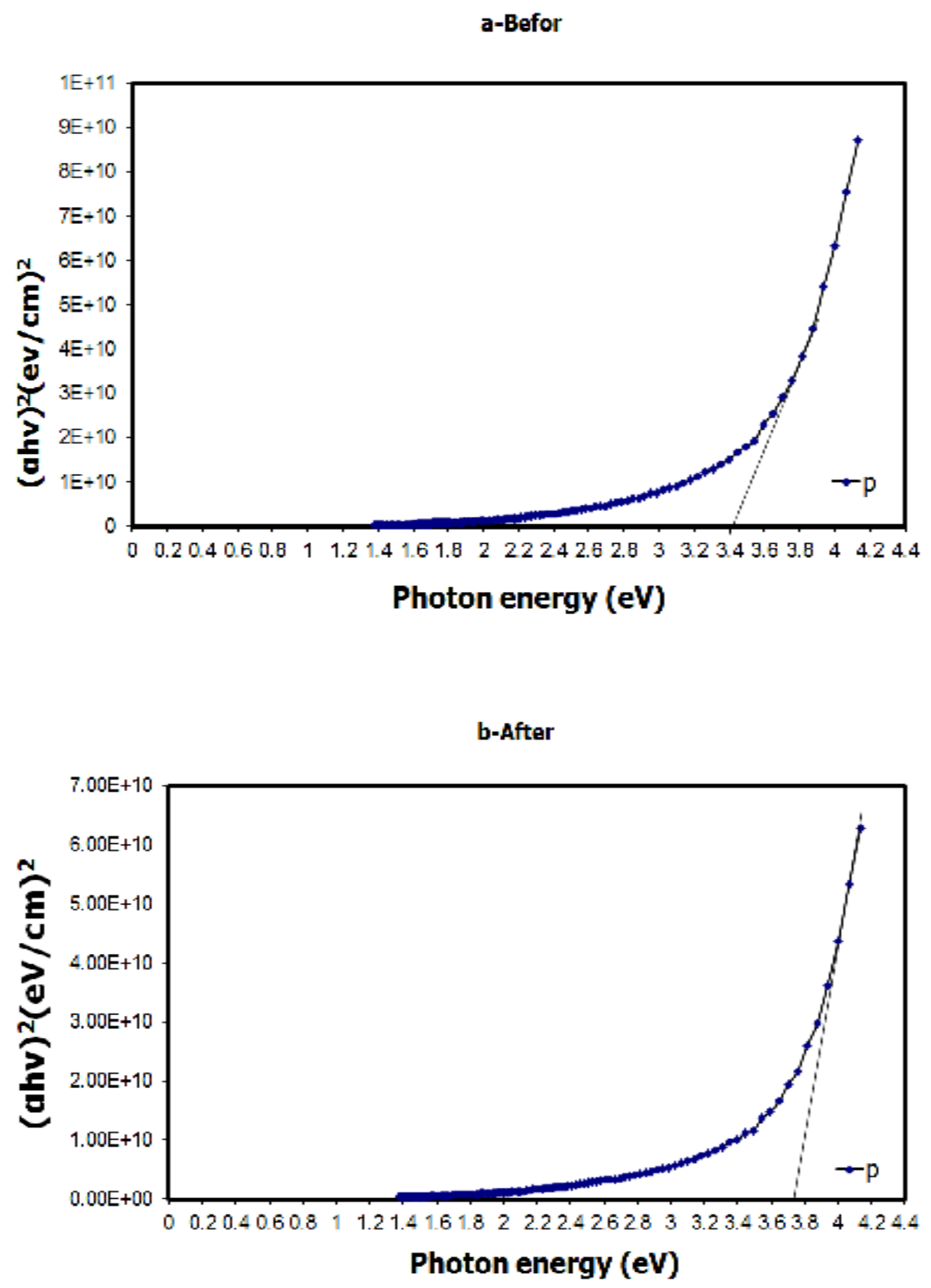

Fig. 3. $(\alpha h v)^{2}$ versus photon energy before and after annealing. 

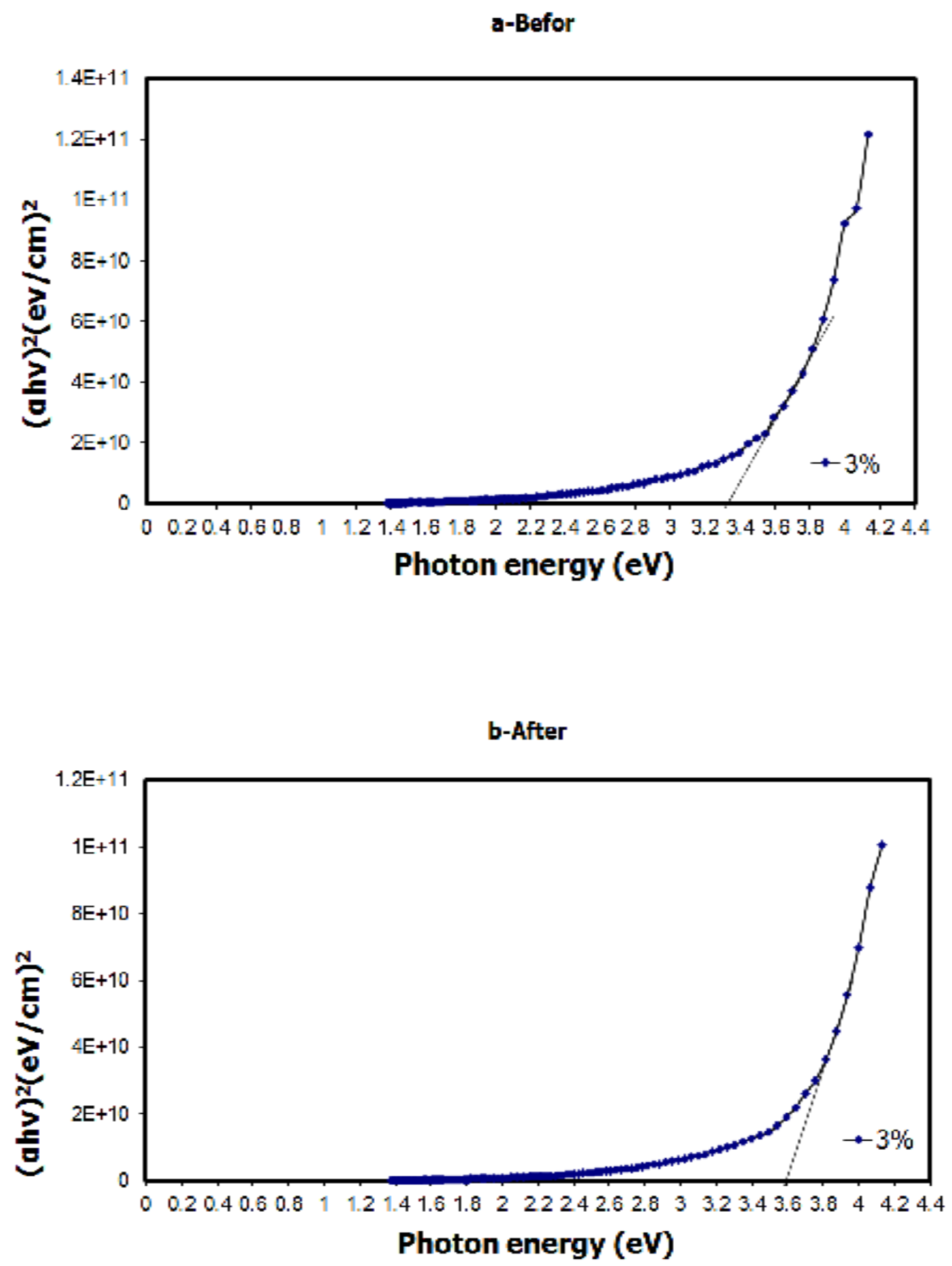

Fig. 3(continue). $(\alpha h v)^{2}$ versus photon energy before and after annealing. 
a-Befor

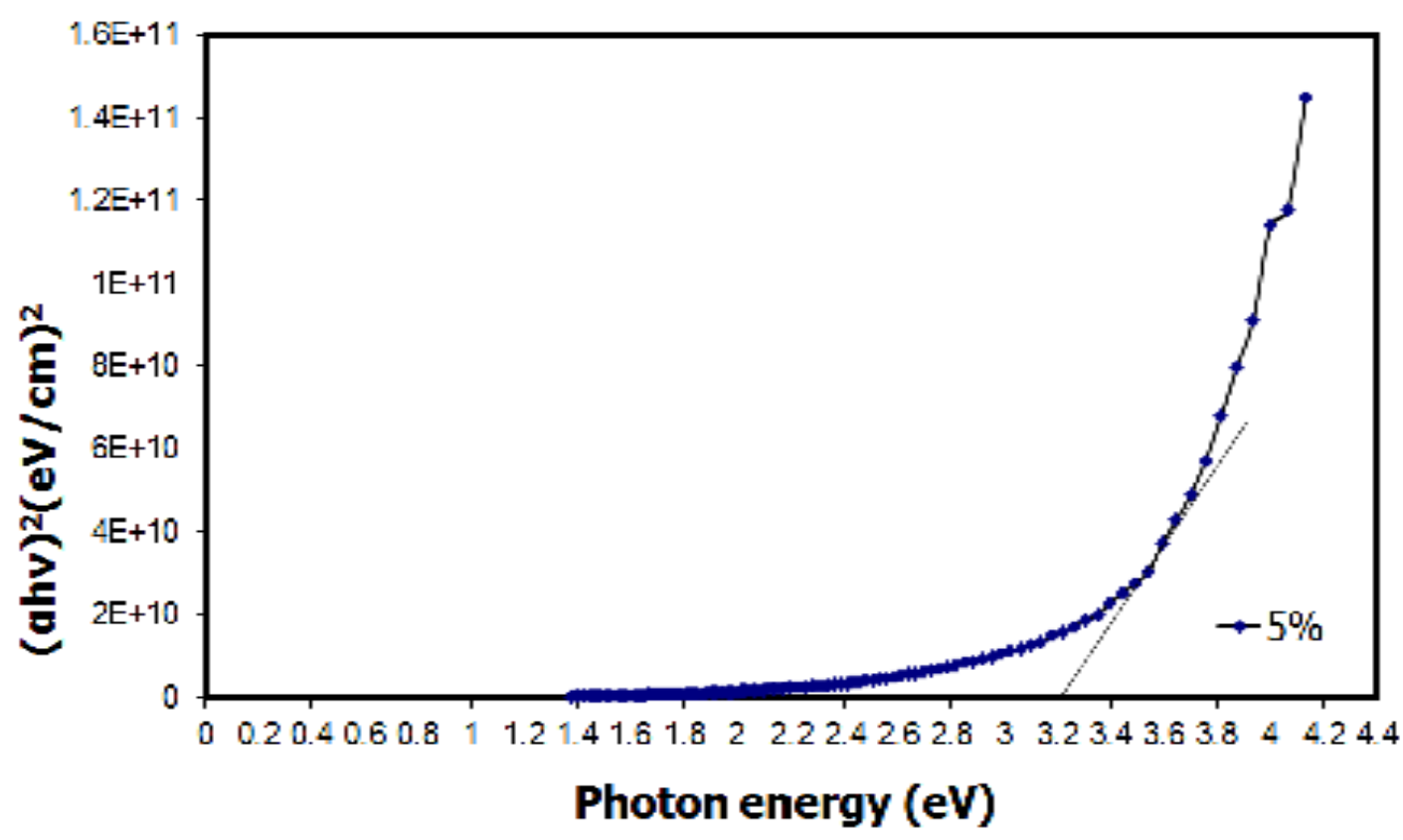

\section{b-After}

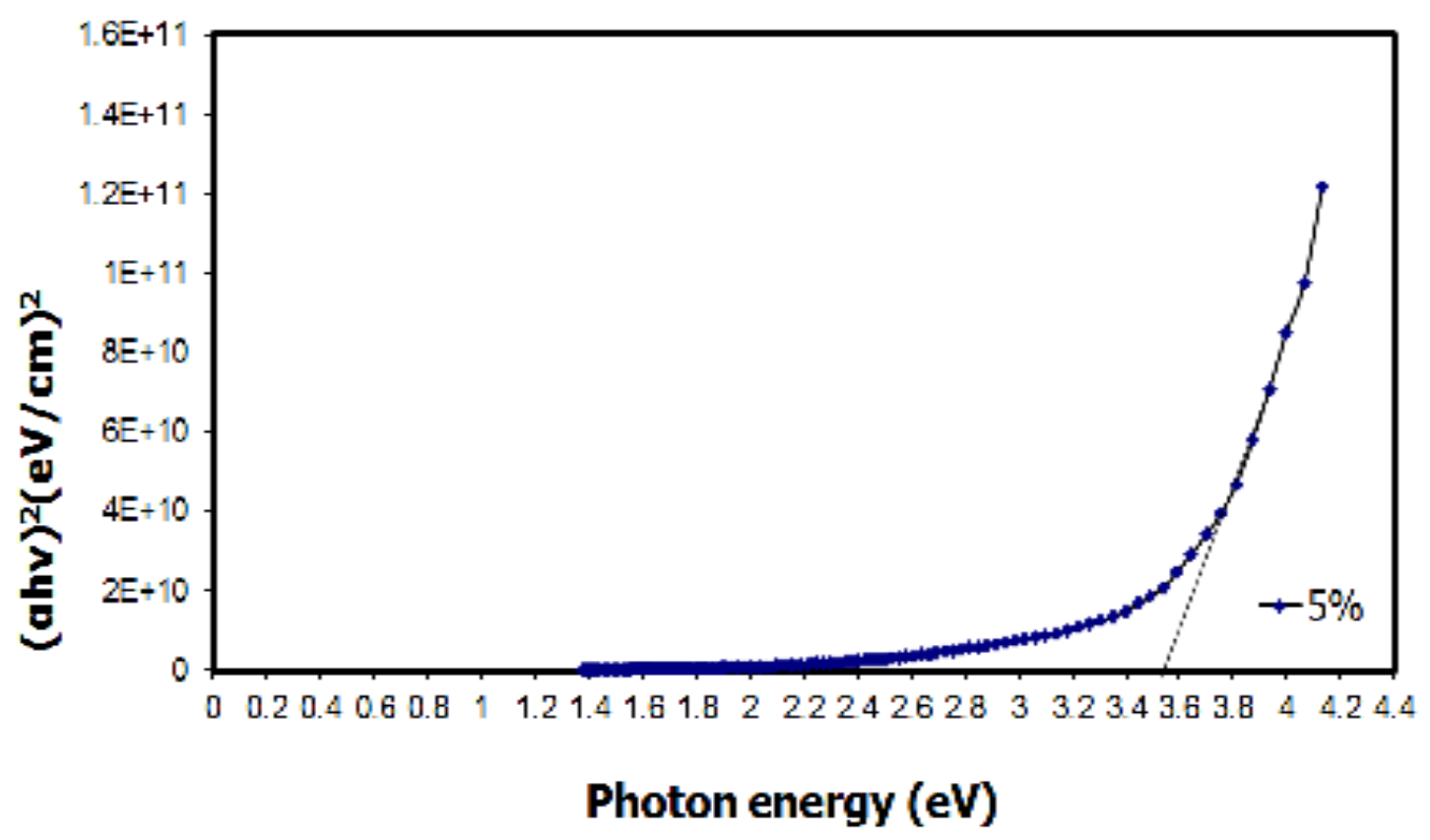

Fig. 3(continue). $(\alpha h v)^{2}$ versus photon energy before and after annealing. 


\section{a-Befor}

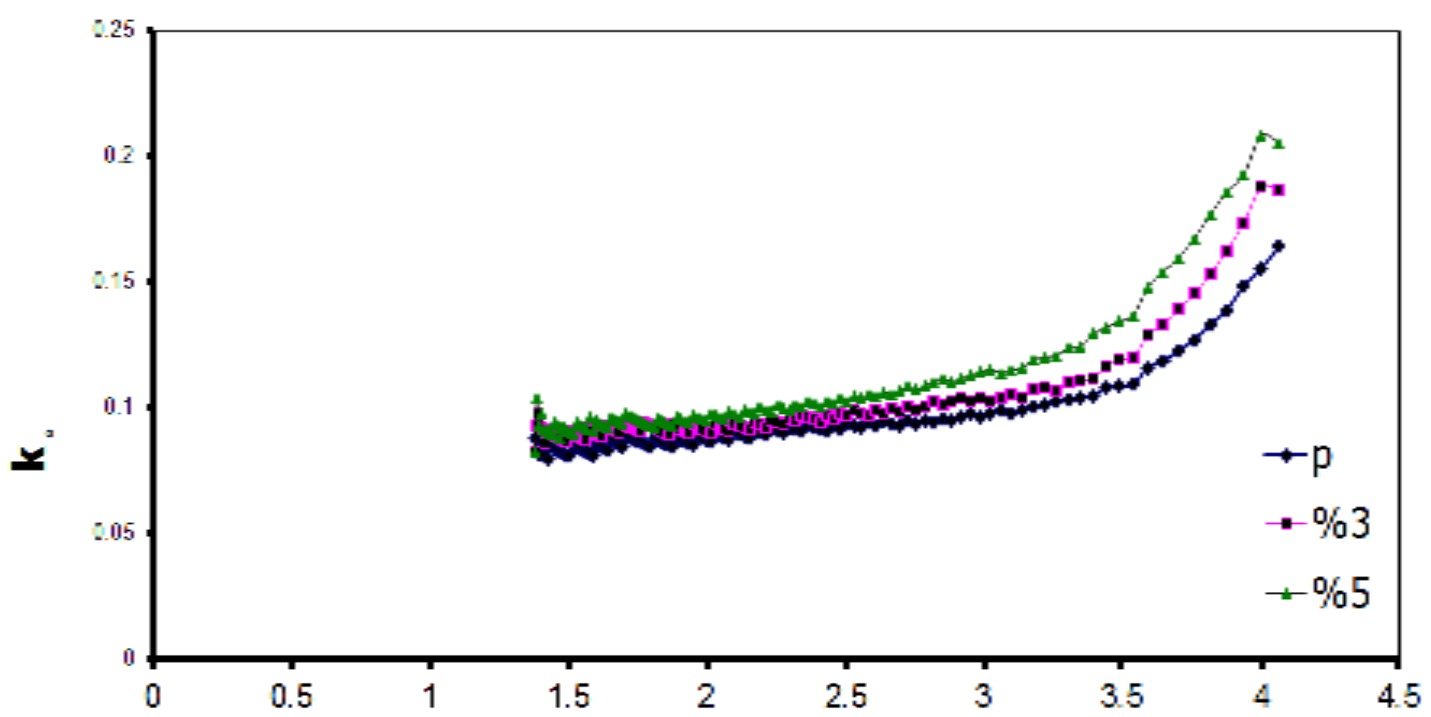

Photon energy (eV)

b-After

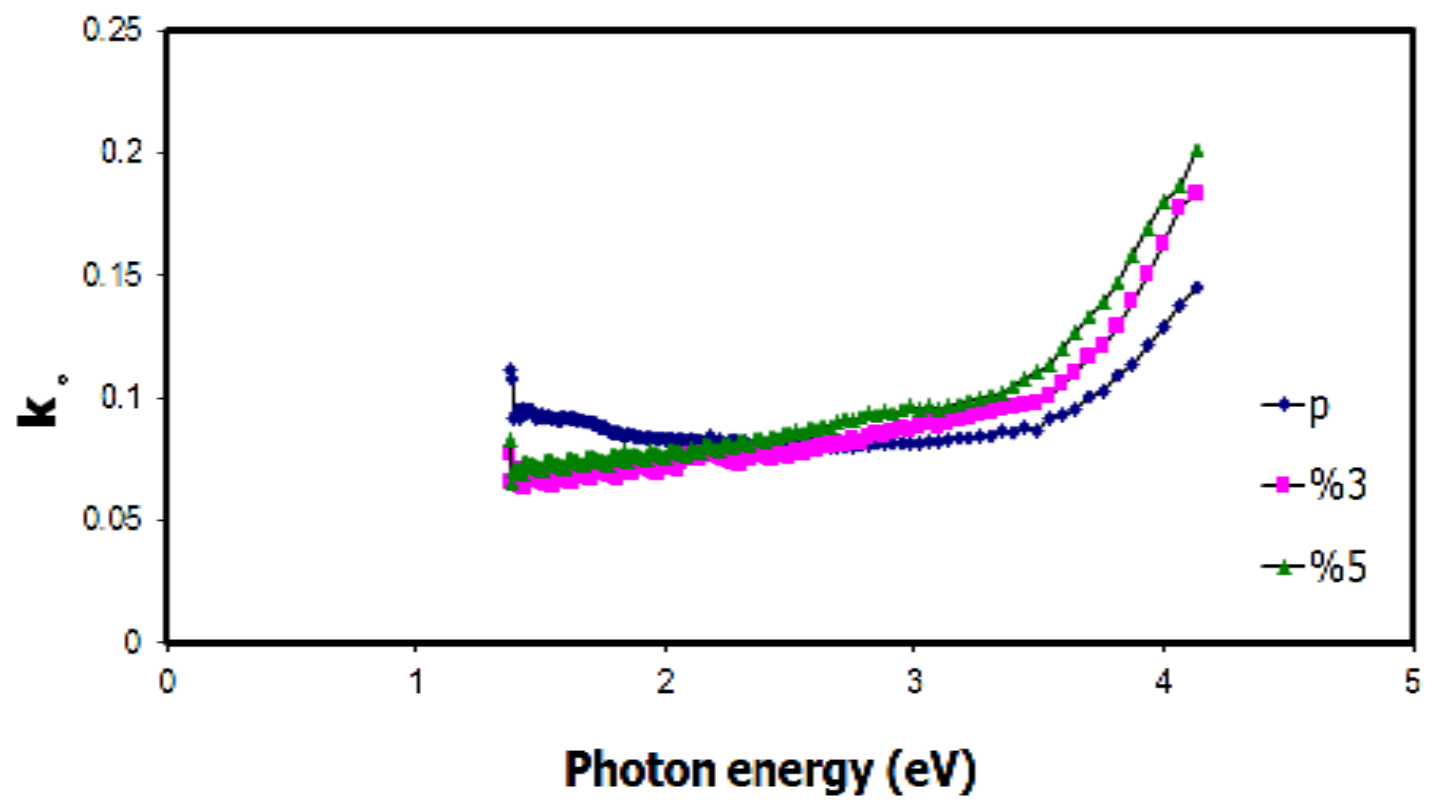

Fig. 4. Extinction cefficient versus photon energy before and after annealing. 

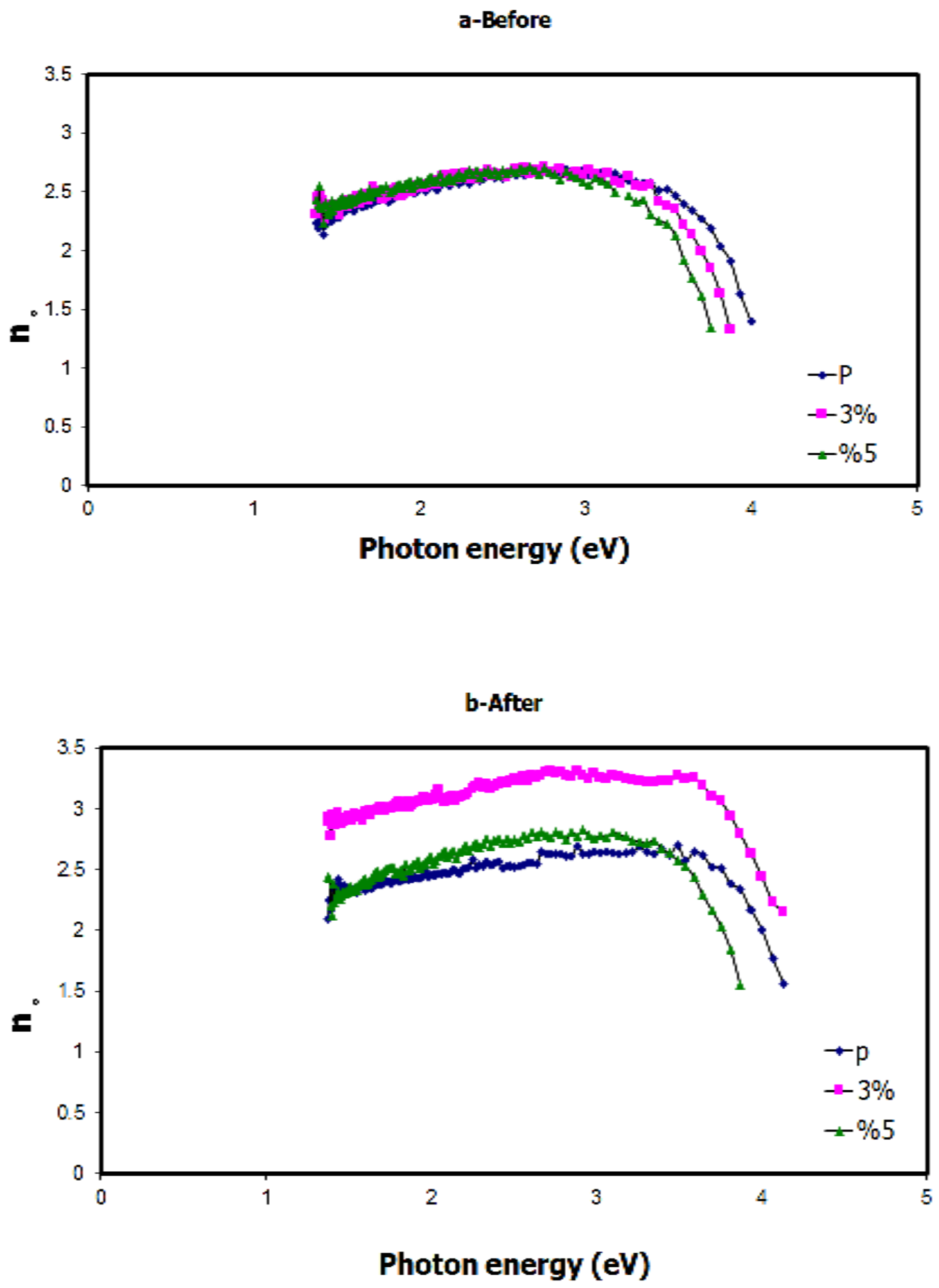

Fig. 5. Refractive index versus photon energy before and after annealing. 


\section{CONCLUSIONS}

In the present work, the effect of annealing treatment on the optical properties of $\left(\mathrm{SnO}_{2}: \mathrm{Co}\right)$ which being deposited by (SP) technique has been studied. The refractive index in $\mathrm{SnO}_{2}$ and $\mathrm{SnO}_{2}$ :Co films vary with varying the composition by non-linear relation. The refractive index increased after heat treatment due to the increasing in the films compactness. The direct optical transition was also mentioned as their values was decreased with cobalt concentration, before and after annealing.

\section{References}

[1] H. Rinnert, P. Miska, M. Vergnat, G. Schmerber, S. Colis, A. Dinia D. Muller, G. Ferblantier, A. Slaoui, Applied Physics Letters 100 (2012) 101908.

[2] Dengkui Miao, Qingnan Zhao, Shuo Wu, Zhendong Wang, Xingliang Zhang, Xiujian Zhao, Journal of Non-Crystalline Solids 356 (2010) 2557-2561.

[3] T. Serin, N. Serin, S. Karadeenz, H. Sari, N. Ugluoglu, O. Pakma, Journal of noncrystalline solid 352 (2006) 209-215.

[4] Seung-Yup Lee, Bynug-O. K. Park, Thin solid films 510 (2006) 154-158.

[5] Shadia J. Ikhmayies, Riyad N. Ahmad-Bitar, Applied surface science 225 (2008) 2627-2631.

[6] E. Csetinorgu, S .Goldsmith, R. L. Boxman, Thin solid film 515 (2006) 880-884.

[7] G. Korotchenkov, V. Brynzaring, S. Dmitriev, Materials Science and Engineering B 56 (1999) 195-204.

[8] A. M. Baranov, Y. A. Malov, D. F. Zaretsky, S. A. Tereshin, Solar Energy Materials \& Solar Cells 60 (2000) 11.

[9] Yun-Hyuk Choi, Myung Yang, Seong-Hyeon Hong, Sensors and Actuators B 134 (2008) 117-121.

[10] D. W. Sheel, H. M. Yates, P. Evans, U. Dagkaldiran, A. Gordijn, F. Finger, Z. Remes, M. Vanecek, Thin Solid Films 517 (2009) 3061-3065.

[11] Willian C. Dickinson, Paul N. Cheremisionoff, "Solar Energy Technology", Handbook Part A, p. 498, (1980).

[12] J. I. Pankove, “OpticalProcesses in Semiconductors”, Prentice-Hall, N. J, (1971).

[13] S. O. Kasap, "Principles of Electronic Materials and Devices", 2nd Ed., McGraw-Hill, New York, (2002).

[14] Wighert Thomos, Kring Thomos Woff, Conference on condensed Matter 185 (1993) 279-307.

[15] M. A. Khashau, A. M. EL-Nagger, Optics communications 174 (2000) 445.

[16] Nadir Fadhil Habubi, Sami Salmann Chiad, Saad Farhan Oboudi, Ziad Abdulahad Toma, International Letters of Chemistry, Physics and Astronomy 4 (2013) 1-8. 
[17] Saad F. Oboudi, Nadir F. Habubi, Ghuson H. Mohamed, Sami S. Chiad, International Letters of Chemistry, Physics and Astronomy 8(1) (2013) 78-86.

[18] J. A. Najim, J. M. Rozaiq, International Letters of Chemistry, Physics and Astronomy 10(2) (2013) 137-150.

[19] Majid H. Hassouni, Khudheir A. Mishjil, Sami S. Chiad, Nadir F. Habubi, International Letters of Chemistry, Physics and Astronomy 11 (2013) 26-37.

[20] C. Indira Priyadharsini, A. Prakasam, P. M. Anbarasan, International Letters of Chemistry, Physics and Astronomy 12 (2013) 82-93.

[21] Raid A. Ismail, Nadir F. Habubi, Hussam R. Abid, International Letters of Chemistry, Physics and Astronomy 4 (2014) 37-47.

[22] Hanan R. A. Ali, International Letters of Chemistry, Physics and Astronomy 8 (2014) 47-55. 